\title{
The reliability of the computed tomography perfusion parameters as a predictor of colorectal cancer grade: influence of tumor region of interest position
}

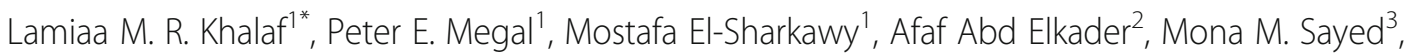
Marwa T. Hussien ${ }^{4}$ and Hanan A. Eltyb ${ }^{5}$

\begin{abstract}
Background: The aim of this study is to prospectively determine whether the computed tomography perfusion (CTP) can predict the tumor grade in colorectal cancer (CRC), and investigation of the best position of the tumor region of interest (ROI) could improve the tumor grade differentiation.

Results: The mean blood flow (mBF) at the tumor edge was significantly different among different tumor grades with the highest value noted in moderately differentiated and the lowest value in poorly differentiated CRC (111.67 \pm 38.91 vs. 52.25 $\pm 21.97 \mathrm{ml} / \mathrm{min} / 100 \mathrm{~g}$, respectively, $P=0.03$ ). At the tumor center, the BF and blood volume (BV) showed highest value in moderately differentiated and the lowest value in poorly differentiated CRC $(P<0.001,0.02$ respectively). The ROC curve revealed that the BF at the tumor edge showed its best results as regard its sensitivity $73.9 \%$ and specificity $82.1 \%$ in the characterization of moderately differentiated CRC from the other subtypes at $>92.2 \mathrm{ml} / 100 \mathrm{~g} / \mathrm{min}$ cut off point and their AUC and $P$ value were $(0.82$ and $<0.001$ respectively), while the AUC of the BF at the tumor center was 0.81 and its $P$ value was 0.03 . In the characterization of poorly differentiated CRC from the other subtypes, BF cut off value at $<67.32 \mathrm{ml} / 100 \mathrm{~g} /$ min at the tumor edge showed the best performance of its sensitivity $88 \%$ and specificity $88 \%$ with 0.92 AUC and $P$ value was $<0.001$, while the AUC of the BF at the tumor center was 0.89 . BF was higher at the edge than at the center of the tumor ( $88.53 \pm 22.45$ vs. $78.79 \pm 28.98 \mathrm{ml} / \mathrm{min} / 100 \mathrm{~g} ; P<0.001$ respectively).

Conclusions: PCT could help in prediction of the poorly and the moderately differentiated CRC and the mBF was the most reliable parameter in prediction of the grade. The variation in $\mathrm{ROI}$ position has no substantial difference in the prediction of the tumor grade; however, this variation has a significant impact on the measurements of the PCT parameters especially the BF.
\end{abstract}

Keywords: Colorectal cancer grades, Multidetector computed tomography, Perfusion

\footnotetext{
* Correspondence: lamiaa_refaat@yahoo.com

'Diagnostic Radiology Department, South Egypt Cancer Institute, Assiut

University, Assiut 71111, Egypt

Full list of author information is available at the end of the article
}

\section{Springer Open}

(c) The Author(s). 2020 Open Access This article is licensed under a Creative Commons Attribution 4.0 International License, which permits use, sharing, adaptation, distribution and reproduction in any medium or format, as long as you give appropriate credit to the original author(s) and the source, provide a link to the Creative Commons licence, and indicate if changes were made. The images or other third party material in this article are included in the article's Creative Commons licence, unless indicated otherwise in a credit line to the material. If material is not included in the article's Creative Commons licence and your intended use is not permitted by statutory regulation or exceeds the permitted use, you will need to obtain permission directly from the copyright holder. To view a copy of this licence, visit http://creativecommons.org/licenses/by/4.0/. 


\section{Background}

Colorectal cancer (CRC) is the third most common cause of cancer deaths worldwide [1]. It was found that grading of CRC has a strong prognostic impact [2], and also has a great impact on the treatment strategy, especially in selecting an adjuvant treatment for high risk stage II CRC patients with poorly differentiated tumor [3]. That is because the poorly differentiated CRC has a high risk for recurrence and unfavorable prognosis [4]. Also, it was found that its 5-year survival rate is significantly lower (29\%) compared to that of the well and moderately differentiated CRC (59\%) [5].

Preoperative specimens from endoscopic colorectal biopsies are often used but are mostly failed to grade tumors because of the lack of sufficient tissue [6]. Perfusion computed tomography (PCT) can quantify the tumor grade noninvasively by measuring the perfusion vascular parameters, including tissue blood flow (BF), blood volume (BV), and permeability surface area product (PS) using the mathematical model [7]. It was reported that the mean blood flow $(\mathrm{mBF})$ is significantly higher in moderately differentiated compared to the well and poorly differentiated CRC [8]. Another study reported that the mBF value was highest in the well-differentiated and lowest in poorly differentiated CRC [9]. Indeed, debate continues regarding the correlation between CRC perfusion parameters and tumor grade, demonstrating the need for further studies in this area. Another point of debate needing more research is position of the tumor region of interest (ROI), that influence the ultimate values and it is unclear which portion of the tumor should be analyzed in computed tomography $(\mathrm{CT})$ perfusion to reflect the tumor grades.

Thus, the purpose of the current study was to prospectively determine whether the CT perfusion parameters can predict the tumor grade in CRC, and investigate the best position of the tumor ROI used to improve tumor grade differentiation. We try to promote these vascular parameters obtained through imaging as a promising alternative for endoscopic colorectal biopsy in patients who are unfit for endoscopy at the time of diagnosis.

\section{Methods}

\section{Patient's selection}

This prospective study was approved by our institutional review board (IRB no. 17100795). Written informed consent was obtained from each patient after receiving information about the details of the study. Between February 2018 till December 2018, 51 patients with CRC that was proved preoperatively by endoscopy were eligible for this study (26 (51\%) males, 25 (49\%) females; mean age, $53.87 \pm 16.13$ years; range, $19-86$ years). The examined tumors were located in rectum $(n=21)$, sigmoid colon $(n=14)$, hepatic flexure $(n=5)$, descending colon $(n=4)$, transverse colon $(n=2)$, ascending colon $(n=4)$, and splenic flexure $(n=1)$, that is based on CT findings and confirmed by endoscopy. Patients were excluded if they had (1) severe renal disease $(n=2),(2)$ preoperative radiation therapy or chemotherapy $(n=4)$, (3) no surgical intervention after CT $(n=0),(4)$ contraindication to contrast media $(n=2),(5)$ no pathological reports $(n=3),(6)$ pathologically benign colorectal mass $(n=10)$, and (7) tumor depth less than $2 \mathrm{~cm}$ based on CT $(n=5)$.

\section{CT technique}

Pre-operative PCT scans were performed on all patients by using a 16 detector CT scanner (Bright Speed, GE Healthcare Technologies). After $4 \mathrm{~h}$ of fasting, $1000 \mathrm{ml}$ of water was ingested $30 \mathrm{~min}$ prior to scanning to opacify the small bowel according to normal practice in our institution. Twenty milligrams of spasmolytic agent hyoscine butylbromide (Buscopan; Boehringer Ingelheim, Ingelheim am Rhein, Germany) was administered intravenously to all patients immediately prior to data acquisition to minimize bowel peristalsis during the CT. Opacification of large intestine with saline was done for all the patients prior to the CT examination, using balloon enema nozzle connected with a tube to an enema bag containing $1.5 \mathrm{l}$ of saline.

An abdominopelvic CT was performed initially to localize the colorectal tumor without IV contrast for cine imaging in perfusion examination using the following parameters $(120 \mathrm{kV} ; 140 \mathrm{~mA} ; 5 \mathrm{~mm}$ slice thickness; $1.5 \mathrm{~s}$ speed; $36 \mathrm{~cm}$ FOV). Identification of the tumor margin was done by two radiologists with consensus (ME and LMRK with experience 15 and 10 years respectively in abdominal CT imaging). Then plan of the perfusion study after coordination of the scan was performed.

For the perfusion study, a pump injector was used to inject $100 \mathrm{ml}$ of iopromide $370 \mathrm{mg}$ of iodine per milliliter intravenously (Ultravist 370; Bayer) at a rate of 5 $\mathrm{ml} / \mathrm{s}$, using the following parameters: $120 \mathrm{kV} ; 100 \mathrm{~mA} ; 5$ $\mathrm{mm}$ slice thickness; 4i/rot speed rotation; FOV $36 \mathrm{~cm}$. Four contiguous sections were obtained, each collimated to $5 \mathrm{~mm}$ (tumor coverage was $2 \mathrm{~cm}$ ). Dynamic PCT scans began $7 \mathrm{~s}$ after the start of IV injection and continued for $65 \mathrm{~s}$. All patients underwent surgery and histopathological study after perfusion PCT was performed.

\section{Image analysis}

Image analysis was performed using commercial software based on deconvolution analysis (Body protocol Perfusion; GE Healthcare Technologies). The radiologists reviewed the images and selected one image that has the best-visualized and the mostly enhanced tumor with consensus.

An arterial input was selected by using the mouse to place a circular ROI $1=20 \mathrm{~mm}^{2}$ in the area of the bestvisualized artery (aorta, iliac, or femoral artery) (Figs. 1a 


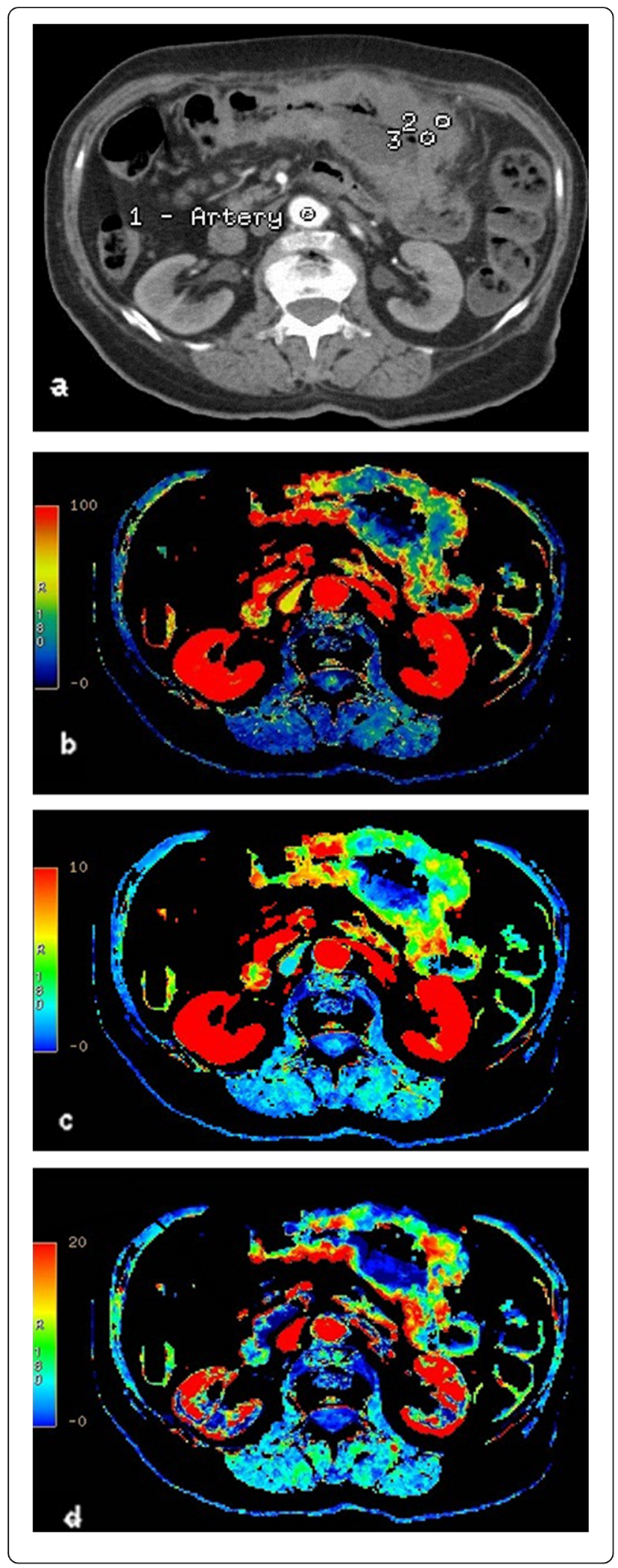

Fig. 1 A 42-year-old man with poorly differentiated cancer of the transverse colon. a Morphologic CT image, demonstrated the position of each ROI, ROI $1=20 \mathrm{~mm}^{2}$ in the artery, $\mathrm{ROI} 2=30 \mathrm{~mm}^{2}$ at the tumor edge, $\mathrm{ROI} 3=30 \mathrm{~mm}^{2}$ at the tumor center. Corresponding parametric color maps (b-d); blood flow (b), blood volume $(\mathbf{c})$, and permeability surface area $(\mathbf{d}) \mathrm{s}$

and 2a). By using the software, the arterial time enhancement curve was done automatically then a parametric map was produced. The mean values of BF, BV, and PS were recorded, also their three perfusion maps (Figs.1b-d and 2b-d) were generated for two ROIs, that is similar in size and different in position; (a) ovoid or circular ROI $2=30 \mathrm{~mm}^{2}$ were manually selected at the most enhanced area at tumor edge (Figs.1a and 2a), (b) another circular or ovoid ROI $3=30^{2} \mathrm{~mm}$ were manually selected that placed at the most enhance area at the tumor center (Figs.1a and 2a). Care was taken to exclude peri-rectal or peri-colonic fat and intraluminal gas when present, by viewing a cine loop of the perfusion CT images. A time attenuation curve for the selected tumor tissue and the mean values for BF, BV, and PS for each ROI were then derived automatically.

\section{Tumor grades}

The surgical specimens were fixed with $10 \%$ formaldehyde and embedded in paraffin. The differentiation of the grades was assessed by an experienced gastrointestinal pathologists and was divided into three subgroups: well, moderately, and poorly differentiated CRC.

\section{Statistical analysis}

Data was collected and analyzed those using SPSS (Statistical Package for the Social Science, version 20, IBM, and Armonk, New York). Continuous data were expressed in the form of mean \pm SD or median (range) while nominal data were expressed in the form of frequency (percentage). A Student $t$ test was used to compare different perfusion parameters with the two positions of the ROIs while the ANOVA was used to compare different perfusion parameters based on grades of CRC. Level of confidence was kept at $95 \% ; P$ value $<0.05$ was considered significant. Sensitivity, specificity, and accuracy for each significant perfusion parameter in the prediction of tumor grade were calculated using cut off values chosen on the basis of receiver operating characteristic (ROC) curves.

\section{Results}

Fifty-one patients underwent surgery after PCT scans; there were 11 (21.6\%), 17 (33.3\%), and 23 (45.1\%) welldifferentiated, poorly, and moderately differentiated CRCs respectively. The difference in the perfusion parameters among different tumor grades at the edge of the tumor was summarized in Table 1, and demonstrated that the mBF was 


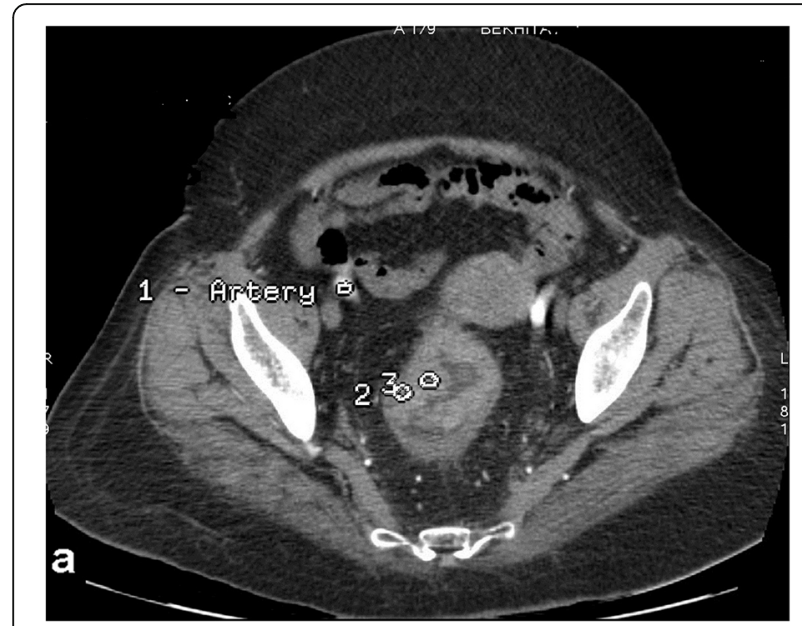

Fig. 2 A 53-year-old women with moderately differentiated cancer of the sigmoid colon. a CT image shows the location of the ROls; $\mathrm{ROI} 1=20 \mathrm{~mm}^{2}$ in the artery, $\mathrm{ROI} 2=30 \mathrm{~mm}^{2}$ at the edge of the tumor, $\mathrm{ROI} 3=30 \mathrm{~mm}^{2}$ at the center of the tumor. Corresponding parametric color maps (b-d); $\mathbf{b}$ blood flow, $\mathbf{c}$ blood volume, and permeability surface area $\mathbf{d}$

significantly different among different tumor grades with the highest value of the BF noted in a moderately differentiated $\mathrm{CRC}$ and the lowest value noted in the poorly differentiated CRC. The highest BF and BV was noted in moderately differentiated CRC at the tumor center with significant difference $(P<0.001,0.02$ respectively), followed by welldifferentiated CRC and the lowest value was noted in the poorly differentiated CRC as summarized in (Table 2).

Because there was a statistically significant difference
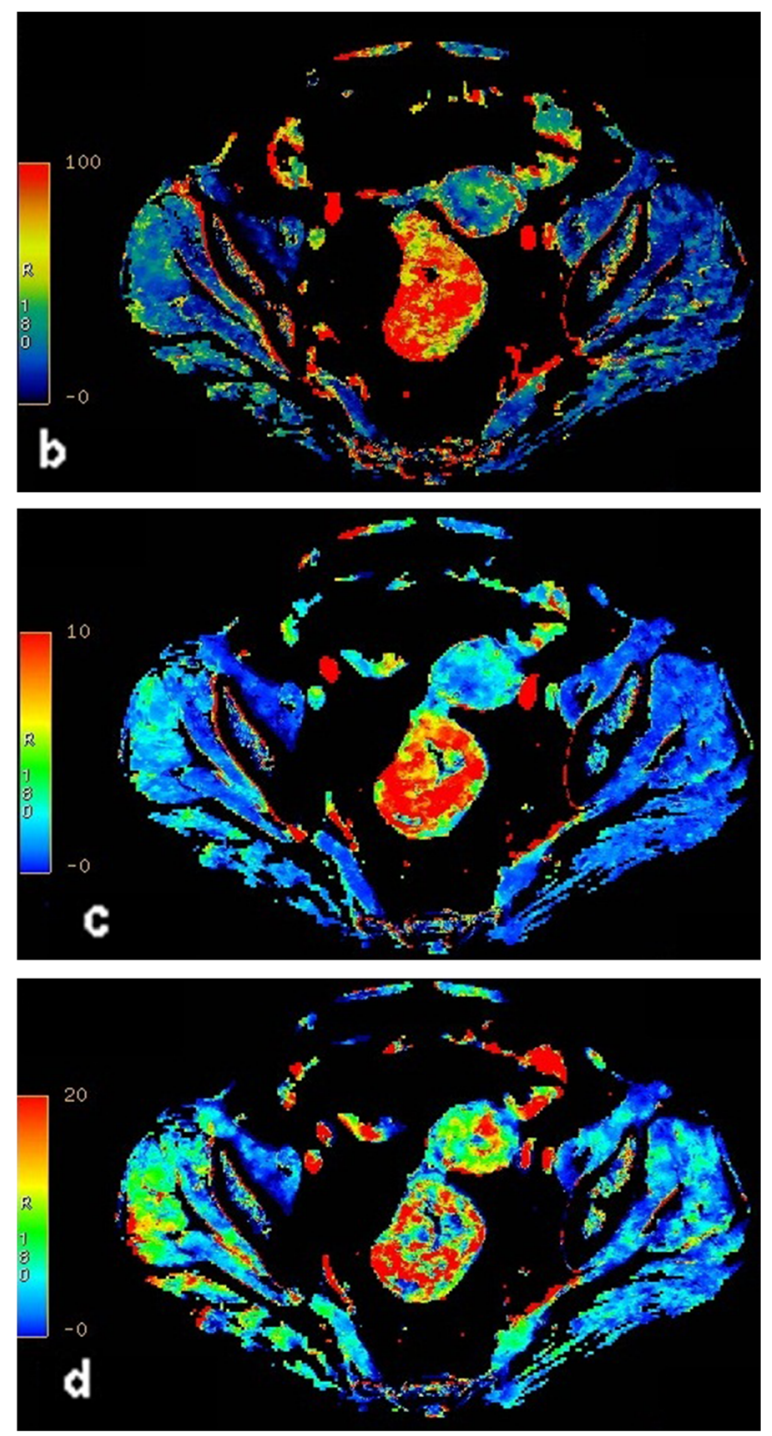
among different grades in $\mathrm{BF}$ at the tumor edge and also in $\mathrm{BF}$ and $\mathrm{BV}$ at the tumor center, so their diagnostic accuracy was assessed using ROC curves. The ROC curve revealed that the $\mathrm{BF}$ value at the tumor edge showed its best results as regard its sensitivity (73.9\%) and specificity $(82.1 \%)$ in the characterization of moderately differentiated CRC from the other subtypes at $>92.2 \mathrm{ml} / 100$ $\mathrm{g} / \mathrm{min}$ cut off point and their area under the curve (AUC) and $P$ value were $(0.82$ and $<0.001$ respectively), while the AUC of the BF at the tumor center was 0.81 and its $P$ value was 0.03 (Fig. 3). The confidence interval of the $\mathrm{BF}$ at the edge and the center of the tumor were (0.701-0.938, 0.684-0.934 respectively).

In the characterization of poorly differentiated CRC from the other subtypes, BF cut off value at $<67.32 \mathrm{ml} /$ $100 \mathrm{~g} / \mathrm{min}$ at the tumor edge showed the best performance of its sensitivity (88\%) and specificity (88\%) with 0.92 AUC and $P$ value was $<0.001$, while the AUC of the BF at the tumor center was 0.89 (Fig. 4). The confidence interval of the $\mathrm{BF}$ at the edge and the center of the tumor were $(0.000-0.171,0.003-0.208$ respectively)

The AUC and the specificity of the BF at the edge and the center of the tumor in diagnosis of welldifferentiated CRC were low (0.58 and 0.64 respectively) and $(47.5 \%, 50 \%$ respectively), but its sensitivity at the edge and center was high (90.9\%, 90\% respectively).

The AUC of the BV at the edge and center of the tumor in the diagnosis of the moderately, poorly, and well-differentiated CRC were low (0.63 and 0.65-0.75 and $0.77-0.56$ and 0.46 respectively).

Perfusion parameters of colorectal cancer at the tumor edge and tumor center using $30 \mathrm{~mm}^{2}$ ROI are summarized in (Table 3 ) and demonstrated that the $\mathrm{mBF}$ was significantly higher at the tumor edge than at the center $(P<0.001)$.

\section{Discussion}

Quantitative PCT measurements are increasingly being used to assess the hemodynamic behavior of the tumor 
Table 1 Correlation of the CT perfusion parameters to the grade of colorectal cancer at the tumor edge using $30 \mathrm{~mm}^{2} \mathrm{ROI}$

\begin{tabular}{lllll}
\hline & Well differentiated & Moderate differentiated & Poorly differentiated & $P$ value \\
\hline Blood flow $(\mathrm{ml} / 100 \mathrm{~g} / \mathrm{min})$ & $96.19 \pm 21.20$ & $111.67 \pm 38.91$ & $52.25 \pm 21.97$ & 0.03 \\
Blood volume $(\mathrm{ml} / 100 \mathrm{~g})$ & $7.44 \pm 3.01$ & $7.56 \pm 3.81$ & $5.07 \pm 3.88$ & 0.09 \\
Permeability area $(\mathrm{ml} / 100 \mathrm{~g} / \mathrm{min})$ & $9.90 \pm 6.47$ & $10.80 \pm 7.57$ & $11.15 \pm 6.30$ & 0.89 \\
\hline
\end{tabular}

Data were expressed in the form of a mean (SD). $P$ value was significant if $<0.05$

that could reflect its patho-physiological nature, which may affect the therapeutic decision and patient prognosis. As the treatment strategy should consider not only the stage but also the grade of the tumor, it is worthwhile to try to stratify the tumor grade with a non invasive method like the PCT.

Regarding the grade differentiation of the CRC, we found that measuring the $\mathrm{BV}$ at the edge and center of the tumor was an unreliable predictor of any grade of the CRC as a result of its low values of the AUC and the specificity in the diagnosis of the three grades of the CRC. There were some differences in the $\mathrm{mBF}$ at the edge and center of different CRC grades that could be relied upon in differentiating various subtypes of CRC. The mBF was significantly higher in moderately differentiated than in a well-differentiated CRC and the lowest value was noted in poorly differentiated CRC. There was no statistical significant difference in BV or PS in different tumor grades at the tumor edge. However, at the tumor center, the BV in addition to the BF were significantly higher in moderately than in well differentiated CRC and the lowest values were also noted at the poorly differentiated CRC. Kim et al. [8] also reported that the mBF was significantly increased in moderately differentiated compared to well-differentiated CRC and decreased in poorly differentiated CRC compared to moderately and well-differentiated CRC. They described the lowest value of the $\mathrm{mBF}$ of the poorly differentiated CRC by two hypotheses that supported their results. The first one is that the interstitial pressure in poorly differentiated CRC increase and compresses the small capillaries more than in well and moderately differentiated $\mathrm{CRC}$. The second is that the growth rate of the poorly differentiated CRC is too rapid to develop angiogenesis of mature vessels. However, there are some conflicting results between Sun et al. [9] and our results. They reported that the $\mathrm{mBF}$ was significantly higher in well-differentiated CRC than that in moderately and poorly differentiated CRC, explaining that by the hypothesis of the better the tumor differentiation, the greater the $\mathrm{BF}$ value. There are two reasons that might have led to the difference between Sun et al.'s [9] results and our results. First, Sun et al. [9] used the single ROI that was drawn with freehand method around the peripheral visible boundary of the tumor, but we measured the perfusion parameters at one level of the tumor with definite size of the two ROI. Second, the difference in the software of CT perfusion applications and number of $\mathrm{CT}$ detectors as they used CT with 256 detectors and the software depends on the slope method, that leads to generate a great difference in the quantitative perfusion results [10].

From our study and the previously described studies $[8,9]$, it is obvious that the poorly differentiated CRC could be identified by its hypoperfusion nature, at the edge and the center of the tumor. Our results showed that the sensitivity, specificity, and AUC of the mBF at the edge and the center of the tumor were $88 \%, 94-88 \%$, $85 \%$, and $0.92,0.89$ at $<67.32$ and $<68.45 \mathrm{ml} / 100 \mathrm{~g} / \mathrm{min}$ cutoff point respectively. This is the golden result, as we could detect the poorly differentiated CRC that might need adjuvant chemotherapy, and has a poor prognosis. This is so valuable in generally ill and unfit patient, especially with frequent failure of preoperative specimens from endoscopic colorectal biopsies to grade tumors because of the lack of sufficient tissue [6].

The moderately differentiating CRC could be identified by its hyperperfusion nature with $73.9 \%, 73.9 \%$ sensitivity, $82.1 \%, 85.7 \%$ specificity, and $0.82,0.81$ AUC of their $\mathrm{mBF}$ value respectively at the edge and center of the tumor, at specific cut off point $>92.2,>85.2 \mathrm{ml} / 100$ $\mathrm{g} / \mathrm{min}$. It was difficult to identify the well-differentiated CRC at $>67.5$ and $68.5 \mathrm{ml} / 100 \mathrm{~g} / \mathrm{min}$ cut off point at the edge and the center of the tumor respectively, because of the low specificity and AUC values.

Integral to the quantitative assessment of the PCT parameters and the CRC grade in our study, we also assessed the variation in position of the tumor ROI and its relation to the quantitative CT perfusion parameters. We demonstrated that the difference in the position of

Table 2 Correlation of the CT Perfusion parameters to the grade of colorectal cancer at the tumor center using $30 \mathrm{~mm}^{2} \mathrm{ROI}$

\begin{tabular}{lllll}
\hline & Well differentiated & Moderate differentiated & Poorly differentiated & $P$ value \\
\hline Blood flow $(\mathrm{ml} / 100 \mathrm{~g} / \mathrm{min})$ & $83.77 \pm 17.29$ & $98.80 \pm 34.07$ & $48.50 \pm 22.29$ & $<0.001$ \\
Blood volume $(\mathrm{ml} / 100 \mathrm{~g})$ & $7.20 \pm 2.32$ & $7.44 \pm 3.73$ & $4.62 \pm 3.03$ & 0.02 \\
Permeability area $(\mathrm{ml} / 100 \mathrm{~g} / \mathrm{min})$ & $12.15 \pm 7.26$ & $11.10 \pm 6.13$ & $11.13 \pm 4.17$ & 0.87 \\
\hline
\end{tabular}

Data were expressed in the form of a mean (SD). $P$ value was significant if $<0.05$ 


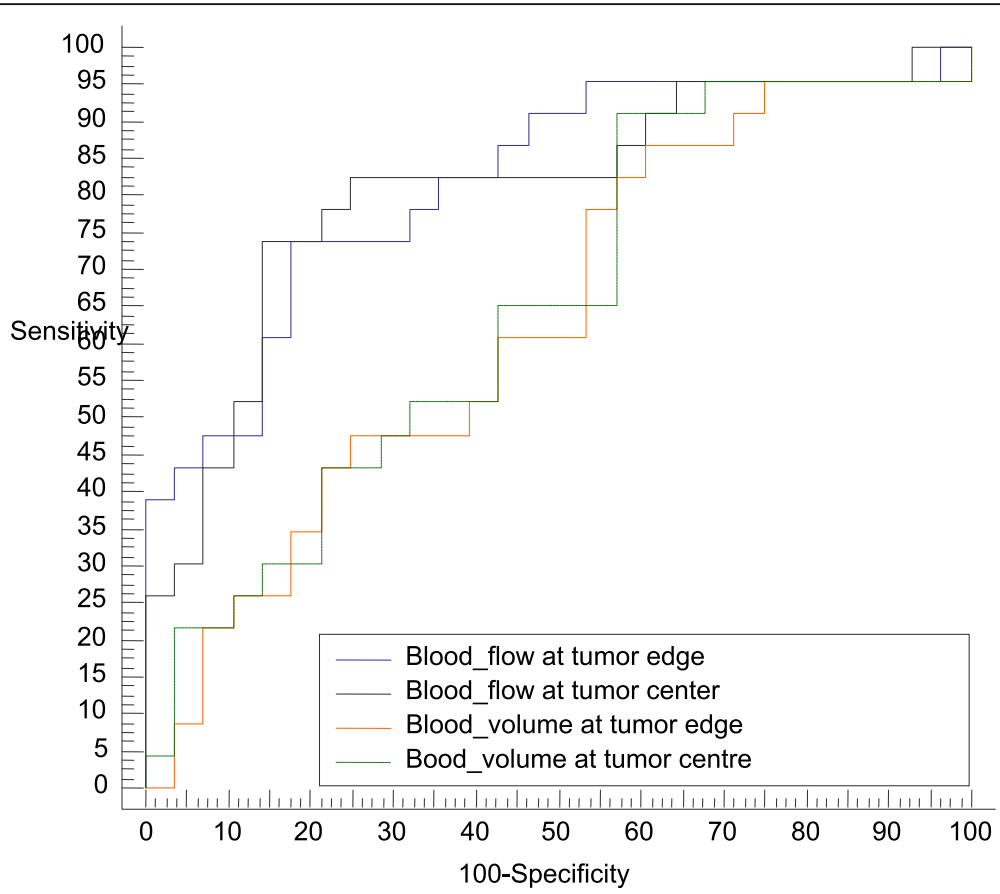

Fig. 3 Diagnostic performance of blood flow and volume in diagnosing moderately differentiated colorectal cancer

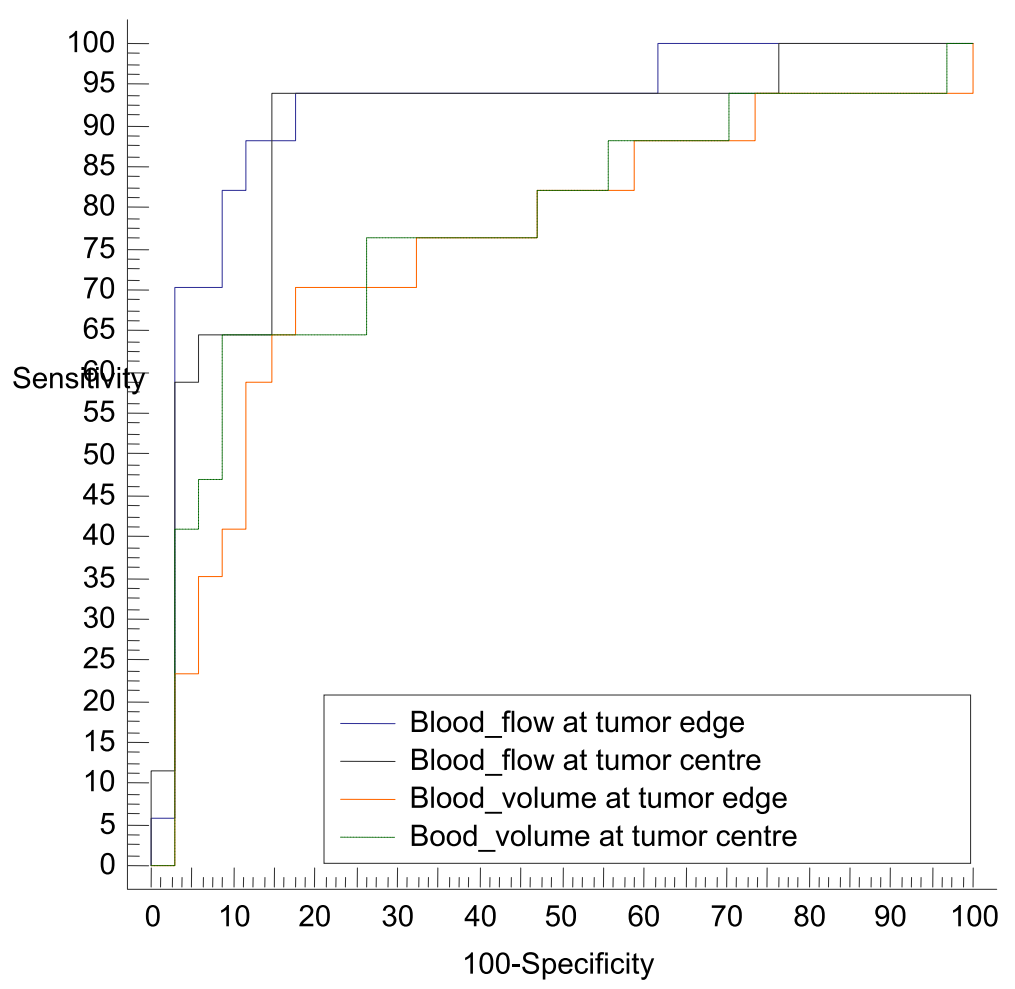

Fig. 4 Diagnostic performance of blood flow and volume in diagnosing poorly differentiated adenocarcinoma 
Table 3 Perfusion parameters of colorectal cancer at the tumor edge and the tumor center using $30 \mathrm{~mm}^{2} \mathrm{ROI}$

\begin{tabular}{llll}
\hline & $30 \mathrm{~mm}^{2} \mathrm{ROl}$ at tumor edge & $30 \mathrm{~mm}^{2}$ ROl at tumor center & $P$ value \\
\hline Blood flow $(\mathrm{ml} / 100 \mathrm{~g} / \mathrm{min})$ & $88.53 \pm 22.45$ & $78.79 \pm 28.98$ & $<0.001$ \\
Blood volume $(\mathrm{ml} / 100 \mathrm{~g})$ & $6.70 \pm 3.79$ & $6.45 \pm 3.44$ & 0.14 \\
Permeability-surface area $(\mathrm{ml} / 100 \mathrm{~g} / \mathrm{min})$ & $10.72 \pm 6.82$ & $11.34 \pm 5.73$ & 0.17 \\
\hline
\end{tabular}

Data were expressed in the form of a mean (SD). $P$ value was significant if $<0.05$

the tumor ROI significantly affect the quantitative measurement of the tumor perfusion parameters specifically the blood flow, as the mBF value was significantly higher at the edge than at the center of the tumor. This finding is concordant with two previous studies $[11,12]$, who reported that the perfusion parameter values of the same ROI size were highest at the tumor edge and lowest at the tumor center. This was explained by the presence of vascular dilatation at the periphery of the tumor compared with that in the center that appeared compressed and elongated [12]. The difference in tumor perfusion between the rim and the center has been noted also in another study that has been done on the rabbits with VX2 liver tumors and reported that the hepatic blood flow and volume were significantly higher at the periphery than at the center of the tumor [13].

We studied the impact of the ROI position in predicting the tumor grade, and we found no substantial difference in the ROI position either at the edge or the center of the tumor in prediction of the tumor grade, as the confidence interval of the BF and BV at the edge and the center of the tumor were overlapped.

There were several limitations to our study. First, the study sample size was small with a few numbers of welldifferentiated CRC cases. Accordingly, a study with a larger number of patients is needed. Second, the CT scans were performed using 16 rows CT scanner, so perfusion scan was performed on just $2 \mathrm{~cm}$ thickness of the tumor, not whole-tumor perfusion. Third, we measured the perfusion parameters at one level of the tumor with definite size of the ROI and considered this measurement as a reflection of the perfusion of the whole tumor. Lastly, radiation hazards still remain a limitation in perfusion CT.

\section{Conclusions}

The PCT could help in prediction of the CRC grade, especially the poor and the moderately differentiated CRC. The $\mathrm{mBF}$ is the most reliable PCT parameter that could be relied upon in this issue. The variation in ROI position has a great impact on quantitative measurements of the perfusion parameters, specifically the BF which is higher at the edge than at the center of the tumor. However, this variation has no substantial difference in the prediction of the tumor grade.

\section{Abbreviation}

PCT: Perfusion computed tomography; CT: Computed tomography; CRC: Colorectal cancer; ROI: Region of interest; BF: Blood flow; mBF: Mean blood flow; BV: Blood volume; PS: Permeability surface area; SPSS: Statistical Package for the Social Science; ROC: Receiver operating characteristic; AUC: Area under the curve

\section{Acknowledgments}

This research did not receive any specific grant from funding agencies in the public, commercial or not for the profit sectors. Guarantor: the scientific guarantor of this publication is Dr. Lamiaa Mohammed Refaat Khalaf.

\section{Ethical approval and consent to participate}

This prospective study was approved by the Research Ethics Committee of the Faculty of Medicine at Assiut University in Egypt in (IRB no. 17100795). Written informed consent was obtained from each patient after receiving information about the details of the study.

\section{Authors' contributions}

LMRK: Dr. Lamiaa was responsible for study design, revision and interpretation of the perfusion images for all the patients who enrolled in this study, analysis and interpretation of the data, statistical analysis, editing, drafting, and submission of the manuscript. Guarantor of integrity of the entire study. PEM: Dr. Peter was responsible for data acquisition, statistical analysis, and performance of all the perfusion study and clinical studies. ME: Dr. Mostafa was responsible for study concept, revision, and interpretation of the perfusion images for all the patients who enrolled in this study. AAE: Dr. Afaf was responsible for final approval and revision of the manuscript before its submission. MMS: Dr. Mona was responsible for data acquisition and analysis, accuracy of the references, examination, and referral of all the patients to the radiodiagnosis department. $\mathrm{MTH}$ : Dr. Marwa was responsible for quality control of the data, revision all the pathological specimen after surgery, and writing the pathological part of the manuscript. HAE: Dr. Hanan was responsible for data acquisition. All authors have approved and read the manuscript.

\section{Funding}

The authors state that this work has not received any funding.

\section{Availability of data and materials}

The datasets used and/or analyzed during the current study are available from the corresponding author on reasonable request.

\section{Competing interest}

The authors whose names are listed on the title page and shared in the Manuscript entitled: "The Reliability of the Computed Tomography Perfusion Parameters as a Predictor of Colorectal Cancer Grade: Influence of tumor Region of Interest position," certified that they have no affiliations with or involvement in any organization or entity with any financial interest (such as honoraria, educational grants, participation in speakers, membership, employment, consultancies, stock ownership, or other equity interest; and expert testimony or patent-licensing arrangements), or non-financial interest (such as personal or professional relationships, affiliations, knowledge or beliefs) in the subject matter or materials discussed in this manuscript.

\section{Consent for publication}

All patients included in this research gave written informed consent to publish the data contained within this study.

\section{Author details}

${ }^{1}$ Diagnostic Radiology Department, South Egypt Cancer Institute, Assiut University, Assiut 71111, Egypt. ²Diagnostic Radiology Department, Faculty of 
Medicine, Assiut University, Assiut 71111, Egypt. ${ }^{3}$ Radiation Oncology Department, South Egypt Cancer Institute, Assiut University, Assiut 71111, Egypt. ${ }^{4}$ Pathology Department, South Egypt Cancer Institute, Assiut University, Assiut 71111, Egypt. ${ }^{5}$ Medical Oncology Department, South Egypt Cancer Institute, Assiut University, Assiut 71111, Egypt.

Received: 17 December 2019 Accepted: 17 March 2020

Published online: 23 March 2020

\section{References}

1. Jurgen W, Moritz K, Jurgen D et al (2005) Colorectal cancer. Lancet 365:153-165

2. Compton CC, Fielding LP, Burgart $L$ et al (2000) Prognostic factors in colorectal cancer. College of American Pathologists Consensus Statement 1999. Arch Pathol Lab Med. 124:979-994

3. Labianca R, Nordlinger B, Beretta GD, Osconi SM, Mandala AC (2013) Early colon cancer: ESMO Clinical Practice Guidelines for diagnosis, treatment and follow-up. Ann Oncol. 24:64-72

4. Benson A, Schrag D, Somerfield M et al (2004) American Society of Clinial Oncology recommendation on adjuvant chemotherapy for stage II colon cancer. J Clin Oncol 22:3408-3419

5. Burton S, Norman AR, Brown G, Abulafi AMSR (2006) Predictive poor prognostic factors in colonic carcinoma. Surg Oncol. 15:71-78

6. Fleming M, Ravula S, Tatishchev SF et al (2012) Colorectal carcinoma: pathologic aspects. J Gastrointest Oncol. 3:153-173

7. Goh V, Halligan S, Daley F, Wellsted DM, Guenther T, Bartram CI (2008) Colorectal Tumor vascularity: quantitative assessment with multidetector $\mathrm{CT}$-do tumor perfusion measurements reflect angiogenesis? Radiology 249(2):510-517. https://doi.org/10.1148/radiol.2492071365

8. Kim JW, Jeong YY, Chang NK et al (2012) Perfusion CT in colorectal cancer : comparison of perfusion parameters with tumor grade and microvessel density. Korean Journal of Radiology 13(8261)

9. Sun H, Xu Y, Yang Q, Wang W (2014) Assessment of tumor grade and angiogenesis in colorectal cancer: whole-volume perfusion CT. Acad Radiol. 21(6):750-757. https://doi.org/10.1016/j.acra.2014.02.011

10. Goh V, Halligan S (2007) Quantitative tumor perfusion assessment with multidetector CT: are measurements from two commercial software packages interchangeable? Radiology 242:777-782

11. Goh V, Halligan S, Gharpuray A, Wellsted D, Sundin J, Bartram CI (2008) Quantitative assessment of colorectal cancer tumor vascular parameters by using perfusion CT: influence of tumor region of interest. Radiology 247(3): 726-732. https://doi.org/10.1148/radiol.2473070414

12. Konerding MA, Fait EGA (2001) 3D microvascular architecture of precancerous lesions and invasive carcinomas of the colon. $\mathrm{Br} J$ Cancer. 84: 1354-1362

13. Stewart EE, Chen X, Hadway JLT (2006) Correlation between hepatic tumor blood flow and glucose utilization in a rabbit tumor model. Radiology 239 740-750

\section{Publisher's Note}

Springer Nature remains neutral with regard to jurisdictional claims in published maps and institutional affiliations.

\section{Submit your manuscript to a SpringerOpen ${ }^{\circ}$ journal and benefit from:}

- Convenient online submission

- Rigorous peer review

- Open access: articles freely available online

- High visibility within the field

- Retaining the copyright to your article

Submit your next manuscript at $\boldsymbol{\nabla}$ springeropen.com 